\title{
Cost - Value - Profit Analysis and Target Costing with Fuzzy Logic Theory
}

\section{Gökhan Baral}

\author{
Assist. Prof. Dr. Sakarya University; baral@sakarya.edu.tr
}

\section{Doi:10.5901/mjss.2016.v7n2p21}

\begin{abstract}
Cost - value - profit ( $C-V-P)$ analysis tries to determine the effects on the profit that will be provided of the changes on the factors required for the purpose of profit planning. C-V-P analysis is a type of analysis that the businesses used for the decisions to get profit. Making a correct profit planning and determining the business decisions for the purpose of the control of the business according to these issues is directly related to realistic costing. The aim of Target Costing is determining the costs that will provide the desired profit. Target Costing is related to costing and profit planning. The way providing the desired profits of the businesses is possible to know and manage the costing in the world that the sale cost are stabilized and easy to learn.In case of monotype production, in Cost-Value-Profit analysis with Fuzzy Logic in case of monotype production Poultry Farm Case: the rules are gathered by the experiences of the director and the profit result has calculated by the profit parameters that are determined by the director. The aim of this study is declaring the existence of new method instead of a traditional method; fuzzy logic theory and showing that it is a practical and simple method that requires minimum resource for cost estimates and profit planning on uncertain situations.
\end{abstract}

Keywords: Cost - Value - Profit Analysis, Target Costing, Fuzzy Logic

\section{Introduction}

Today's business administrators are against diminishing the decision time, increasing the quality, reaching the lowest costs and accelerating the product/service innovation in order to challenge in the world that is increasingly becoming smaller; all of aforementioned actions consist the renewal of the decision operations by the directors.

When the fluctuations in the market are exactly unpredictable, the directors have to decide an atmosphere of uncertainty. In such cases activation decisions are totally connected to intuition, common sense, logic and experience of the directors, instead of exact, net and correct data. Fuzzy Logic can be used for the estimations based on the uncertain concepts that the profit level is disputable as "Is the profit god or not?

The difference between planned profit and real profit is directly connected to fluctuations on cost, sale cost and sale volume. It is required for the directors that understanding these complex relations in order to be successful in planning and control phase. If the directors understand these relations, they can major on the products and strategies that they can get the maximum profit.

Because of such reasons it has to seriously studies on a method that can calculate cost estimations and planning incomes and diminishing the difference between the real results and planned results.

In uncertain situations, thinking and interpretation process of the person contains fuzzy factors. The person generally use ambiguous terms such as low-high, fast-slow, heavy-light in his mind. Unless he added such kind of ambiguity to his decision model it is considered that real situations are not reflected correctly. This may cause faulty decisions. Fuzzy specialty system improves the cognitive structuring of a problem by structuring the uncertain information as represented in mind.

The aim of our study is showing how fuzzy logic concept can be used in target costing applications and establishing fuzzy logic approach in order to analyse the relations between the uncertainty variations.

\section{Fuzzy Logic Transactions}

The real world is complex. This complexity is caused due to uncertainty and inexact considerations and decisions. Uncertainties always can be found because of immaturity of the human considerations on social, economic and technical issues totally. The computers that are developed by human cannot process such kind of uncertainties and they need digital information in order to operate. It is not totally possible to comprehend a real event because of lack of information of human knowledge; human interprets by animating these events in thought system and mind approximately. Difference 
from the computers, human has the capability of making transactions with approximate thinking and insufficient, inadequate and uncertain data and knowledge. Generally the knowledge resources as the complexity and uncertainty outsourcing by different formats are called as fuzzy logic sources (Şen 2004: 10-15).

The business administrators can make decision the presence of knowledge (certainty). It is not possible to make exact predictions about the future because of the improvements on economic life, factors related to investment, challenge, technological developments, changes on consumers pleasures and preferences, disputes between employer employee and other factors (Akgüç 1998:393). This issue makes the business administrators (decision makers) decide under uncertain conditions.

Fuzzy Logic is one of the mathematic models that are beneficial for calculating uncertainties flexibly. The most significant chance that fuzzy clusters represent is presenting blunt limits between the clusters that mean being element of a cluster by being an element of other cluster with membership degree instead of classical clusters (Şen 2004: 21).

The first of the situations that fuzzy logic is valid; the event that is examined is too complicated and placing the view and value judgement of persons in case of lack of information about this issue, the second one is; the case that requires understanding and judgement of person. Fuzzy Logic Principles support to investigate such kind of knowledge resources (Şen 2004: 20).

1) General Knowledge Base Unit; contains input variations and all information about this that the examined case is exposed to. This is also be called as database or input name. The reason why it is called as general database is the data here could be digital and/or oral.

2) Fuzzy Rule Base Unit; contains all of the rules that can be written as IF-THEN and connecting the entries to output variations in a database. All range (fuzzy clusters) connections are thought that can be between given input or outputs on writing such rules. By the way each rule connects the part of input space to output space logically. All of these contexts constitute the rule base.

3) Fuzzy assumption Motor Unit: is a mechanism of transactions community that provide one output that are established between input and output fuzzy clusters on fuzzy rule base. This motor is beneficial for determining how assumptions of each rule will create an output under inputs.

4) Output Unit: determines the community of values that are gathered as a result of fuzzy assumption motor and interaction of knowledge and fuzzy rule bases.

\subsection{Cost-Value-Profit Analysis with Fuzzy Logic Theory in the Firms that are Producing Monotype Products:}

Directing a company to the determined aim consciously of which is established to gain profit is possible with rational profit planning. Profit planning meets us considering various factors that determining the profit and providing the harmony between them. Actually there are lots of internal and external factors that determine the profit amount of a business. However all these factors that have a great role on formation of profit can be summed as four groups (Büyükmirza 2006:408):

a) Unit sale prices of product or goods,

b) Sale amounts of products or goods,

c) Unit variable amounts of product or goods,

d) Fix cost of business

Even though there are models that the contingent and random variables that calculates the uncertainty of variables lots of administrators prefer not using these models since they are complicated and expensive for small and middle sized enterprises. Some directors who do not have the experience to make detailed statistical and mathematical analysis cannot use contingent models. Because of that reason the directors need practical and simple methods that diminish these difficulties and required minimum resources to solve profit problems on uncertain situations. Contingent models require standard distribution principles as a normal distribution that will provide flexibility on arranging dynamic business conditions. Both simulation techniques and related inputs require the use of contingent data. However past distributions may not enlighten the future events as a result of his they are insufficient to handle the uncertain situations. Fuzzy logic is a theory that can be used on analyse of the uncertain situations for small and middle sized enterprises. It provides to get the answer of the question ...if...? They can get answer for their questions less than one minute via this method without requiring more comprehensive quantitative information that has to be known on other contingent models. Since the primary target of the administration is providing profit directors can use to reach their targets while they are constituting their action plans and checking these plans they can use fuzzy logic theory (Yuan 2007:1). 


\subsection{Implementation}

The concepts; sale cost, sale value, variable cost, fixed cost that are used in the analysis of Cost-Value-Profit is identified fuzzy cluster memberships and implemented in poultry farm that produce monotype product.

Implementation of Fuzzy Logic:

Inside fuzzy logic as a tool of Matlab, mamdani fuzzy assumption method is applied.

Memberships and Limits:

Triangular membership functions have been used in order to solve Cost-Value-Profit analysis with fuzzy logy applications. If we determine our memberships; Sale cost, sale value, contingent cost and fixed cost are our input variables. The limits of the memberships have asked by the specialists and the limits has determined by gathering documents related to limits.

Linguistic Terms:

Specialists' experiences are transferred to program by using linguistic terms of input and output variables such as very low, low, moderate, high, very high.

Linguistic terms such as low, moderate, high can be used for input values as seen below. Linguistic terms such as very low, low, moderate, high, very high can be used for output variable.

Table 1: Linguistic Terms

\begin{tabular}{|l|l|}
\hline Input Variables & \multicolumn{1}{|c|}{ Linguistic Variables } \\
\hline \multirow{2}{*}{ Sale Cost - SC } & Low \\
\cline { 2 - 2 } & Moderate \\
\cline { 2 - 2 } Sale Value - SV & Low \\
\cline { 2 - 2 } & Moderate \\
\cline { 2 - 2 } Variable Cost - VC & High \\
\cline { 2 - 2 } & Low \\
\cline { 2 - 2 } Fixed Cost - FC & High \\
\hline & Low \\
\hline & Moderate \\
\hline & High \\
\hline
\end{tabular}

\begin{tabular}{|l|l|}
\hline Output Variables & Linguistic Variables \\
\hline \multirow{4}{*}{ PROFIT } & Very Low \\
\cline { 2 - 2 } & Low \\
\cline { 2 - 2 } & Moderate \\
\cline { 2 - 2 } & High \\
\cline { 2 - 2 } & Very High \\
\hline
\end{tabular}

Input Variables; are determined as sale cost, sale value, variable cost and fixed cost. The variables used in order to make fuzzy the variables are shown in Table 1. For the profit that is determined as output variable 5 linguistic variables is used.

Fuzzy Rules:

The linguistic variables that the samples are given below are resulted wit (if) with conditioned expressions (rules):

1) SF HIGH, DM LOW, SH HIGH, SM LOW THAN PROFIT VERY HIGH

2) SF HIGH, DM LOW, SH HIGH, SM MOD THAN PROFIT VERY HIGH

3) SF HIGH, DM LOW, SH HIGH, SM HIGH THAN PROFIT VERY HIGH

Recovery from fuzziness

Output of fuzzy assumption mechanism is a fuzzy cluster in output universal cluster. Because of that reason it has to be converted to a value that is not fuzzy. This conversion operation is called as "purifying". Firstly a fuzzy output cluster that is constituted by membership values for each rule that has been detected in output universal cluster. Then purifying method is used on the logical compound cluster that is constituted by these clusters and purifying transaction is performed by finding single output value. The gathered value is the output value that the fuzzy logic controller will apply to the system (Elmas 2003: 155).

A fuzzy cluster as a result of a fuzzy cluster transaction has to be required to be converted to odd number. This is 
performed via purifying operation that is the counter operation of the fuzziness transaction (Şen 2004: 92).

Cost-Value-Profit analysis via Fuzzy Logic in case of Monotype Production (Poultry Farm Case):

The poultry farm is located in Avdan Town-Taraklı District-Sakarya Province; it has the capacity of growing up to 20.000 chickens. Chicks are brought to poultry farm by the integrated cutting company and when they grow up they are brought to be cut by the same company. Poultry farm is responsible for grow up activity of the chickens. The production of the monotype; in poultry farm case, the memberships; is constituted by sale cost, sale value, variable cost and fixed cost.

Table 2: The memberships of poultry farm

\begin{tabular}{|l|l|l|l|}
\hline Input Variables & Range & Linguistic Variables & Parameters \\
\hline \multirow{3}{*}{ Sale Cost - SC } & \multirow{3}{*}{$1980-2020$} & Low & $1980-2000$ \\
\cline { 3 - 4 } & & Moderate & $1990-2010$ \\
\cline { 3 - 4 } & & High & $2000-2020$ \\
\hline \multirow{3}{*}{ Sale Value - SV } & \multirow{3}{*}{$37-44$} & Low & $37-40$ \\
\cline { 3 - 4 } & & Moderate & $39-42$ \\
\cline { 3 - 4 } & & High & $41-44$ \\
\hline \multirow{3}{*}{ Variable Cost - VC } & \multirow{3}{*}{$68708-80598$} & Low & $68708-74500$ \\
\cline { 3 - 4 } & & Moderate & $73000-75250$ \\
\cline { 3 - 4 } & & High & $74900-80598$ \\
\hline \multirow{3}{*}{ Fixed Cost - FC } & Low & $3590-3700$ \\
\cline { 3 - 4 } & \multirow{3}{*}{$3590-4030$} & Moderate & $3680-3900$ \\
\cline { 3 - 4 } & & High & $3880-4030$ \\
\hline
\end{tabular}

\begin{tabular}{|l|l|l|l|}
\hline Output Variables & Range & Linguistic Variables & Linguistic Variables \\
\hline \multirow{4}{*}{ PROFIT } & \multirow{4}{*}{$0-15792$} & Very Low & $0-510$ \\
\cline { 3 - 4 } & & Low & $500-1300$ \\
\cline { 2 - 4 } & Moderate & $1260-2550$ \\
\cline { 3 - 4 } & & High & $2500-7300$ \\
\cline { 3 - 4 } & & Very High & $7292-15792$ \\
\hline
\end{tabular}

The value range of the linguistic variables that is determined for the input-output variables of poultry farm application is presented in Table 2 as it will constitute triangular membership function. Parameter data has gathered by the poultry director.

\section{Fuzzy Logic Rules:}

The rule bas of fuzzy systems are formed with if-then-else structures. "And, Or, Not" processors are used as fuzzy processors. The rules that are used for the classification of the poultry farm below. While the certainty levels of the rules are being calculated which rules are valid is determined by benefiting from this rule base.

In case of monotype production, in Cost-Value-Profit analysis with Fuzzy Logic in case of monotype production Poultry Farm Case: the rules are gathered by the experiences of the director and the profit result has calculated by the profit parameters that are determined by the director.

\section{Target Costing}

It is seen that target costing that is gained to English Literature as "Target Costing" in the beginning of 1980s that is applied by the Japanese authors since 1970s (Can 2004: 22).

Target Costing Technique; can be identified as acceptable cost level that will gain the expected profit rate for a product (Şakrak 1998: 314).

\subsection{Usage Causes of Target Costing}

Two important features took place that is accepted related to market and costing on the development of target costing approach. First one is keeping the prices under lesser control than they thought. In real the market is the price determiner and the companies ignoring this can face important dangers. Because of that reason while calculating target costing, estimated market prices is considered. 
The second cause is most of the product costs are being determined during planning and design phase. After a product designed and sent to production, making studies that will change the costing may not be possible (Coşkun 2003: 26).

Target Price is the sale price that is determined by the value that the consumers give according to their perception. Target Profit is the margin that is based on long term profit analyse. Target cost is acceptable costing level that will provide the expected profit rate that belongs to a good (Gökçen 2003: 79-80).

Target costing is a method that is used on the beginning phases before a new product designed and produced. In this method the transactions is diverted to the costumer, major on the production design and spread on the life circle of the product. The aim of the method constitutes the production process that will provide the demanded profit. Organization can provide the harmony between the different parts of the value chain by taking into consideration the profit and costing planning at the same time at the general of this value chain. When the whole of the value chain is taken into consideration it is seen that product development and design phases are very important. Because the research have showed that $80 \%$ of the costing related to production is fixed before the production transaction started. The change of such resources later will cause much more expenses to the business. Since market price based production is not made on target costing concept or it will be produced with appropriate price as in the market the risk of not gaining profit is being diminished. Also lots of business use target costing to guarantee providing profit from new product (Öndaş 2003: 197).

Strategic management that is consistent with all business activities on the competitive requirements that always change and freshen constitutes the movement point of Target Costing Method. However this could be performed by creating appropriate products to the market that based on the customer expectations. Target Costing Method is used to balance costing and profit by taking into consideration the customer satisfaction during new product development process. Because of that reason Target Costing Method is not only a cost reducing method or costing control system but also a part of strategic profit management system that contains value analysis and value engineering. Target Costing Method that is identified as an effective system on the management of the costing that is created on new product design and development phases; consist the profit management of the business on product development phase (Alagöz and Ceran, 2006: 63).

Target costing can be summarized as below (Karakaya, 2004: 585-586):

- Market research is held about the product that will be produced. The functions (comfort, safety, strength, aesthetics, prestige, multipurpose, ease of use) about the product are determined according to consumer need and preferences. The importance that the consumer takes care is also determined.

- The parts that constitutes the product is determined by taking into consideration the determined functions and importance degrees on these. The parts and functions that constitute the product are determined. Market based target costing is determined according to the determined prototype.

- The minimum profit rate (target profit can be determined according to the profit rate that is expected by the investments) is determined that will be gathered by the sales. Target profit is calculated according to the profit rate.

- Calculated target profit is subtracted from sales and target costing is determined. This costing means "Acceptable Maximum Costing".

- Production cost of each part that constitutes the product is calculated. Assumed costing is an estimated cost, it does not claim any target.

- If estimated production costing is bigger than acceptable maximum costing, it is benefited from the cost decreasing techniques. Value engineering and value analysis effective on such point.

- Target cost conformity is to be provided by decreasing the assumed production cost on the acceptable cost level.

\section{Implementation}

Inside fuzzy logic as a tool of Matlab, mamdani fuzzy assumption method is applied.

The poultry farm is located in Avdan Town-Taraklı District-Sakarya Province; it has the capacity of growing up to 20.000 chickens. The production of the monotype; in poultry farm case, the memberships; is constituted by sale cost, sale value, variable cost and fixed cost. Rules are gathered by the experiences of the director and the profit result has calculated by the profit parameters that are determined by the director. 
Table 3. Input and Output Data

\begin{tabular}{|l|l|l|l|}
\hline Input Variables & Range & Linguistic Variables & Parameters \\
\hline \multirow{3}{*}{ Sale Cost - SC } & \multirow{3}{*}{$1980-2020$} & Low & $1980-2000$ \\
\cline { 3 - 4 } & & Moderate & $1990-2010$ \\
\cline { 3 - 4 } & & High & $2000-2020$ \\
\hline \multirow{3}{*}{ Sale Value - SV } & \multirow{3}{*}{$37-44$} & Low & $37-40$ \\
\cline { 3 - 4 } & & Moderate & $39-42$ \\
\cline { 3 - 4 } & & High & $41-44$ \\
\hline \multirow{3}{*}{ Variable Cost - VC } & \multirow{3}{*}{$68708-80598$} & Low & $68708-74500$ \\
\cline { 3 - 4 } & & Moderate & $73000-75250$ \\
\cline { 3 - 4 } & \multirow{3}{*}{ Fixed Cost - FC } & High & $34900-80598$ \\
\hline & \multirow{3}{*}{$3590-4030$} & Low & $3590-3700$ \\
\cline { 3 - 4 } & & Moderate & $3880-3900$ \\
\cline { 3 - 4 } & & High & \\
\hline
\end{tabular}

\begin{tabular}{|l|l|l|l|}
\hline Output Variables & Range & Linguistic Variables & Parameters \\
\hline \multirow{4}{*}{ PROFIT } & & Very Low & $0-510$ \\
\cline { 3 - 4 } & \multirow{4}{*}{$0-15792$} & Low & $500-1300$ \\
\cline { 3 - 4 } & & Moderate & $1260-2550$ \\
\cline { 3 - 4 } & & High & $2500-7300$ \\
\cline { 3 - 4 } & & Very High & $7292-15792$ \\
\hline
\end{tabular}

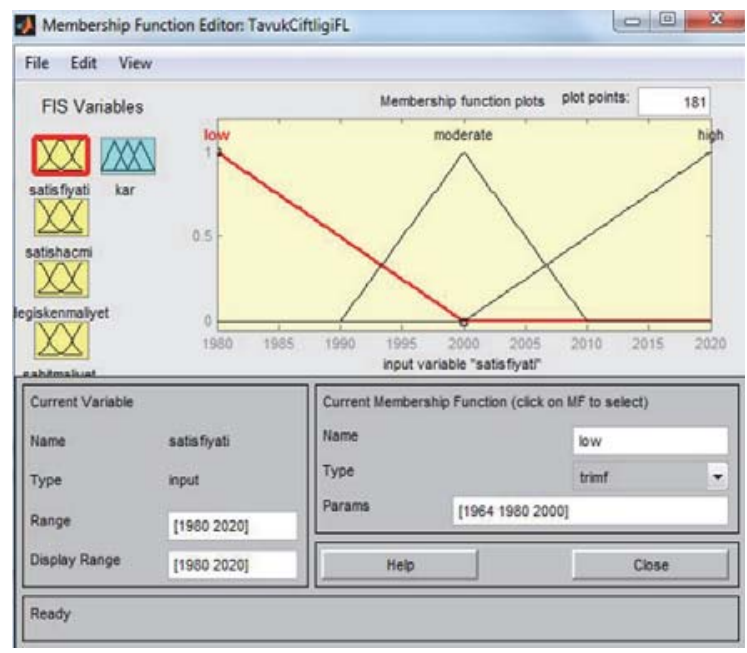

Figure 1: MATLAB fuzzy logic, which is a tool in the view.

(Some words on the figure is written in Turkish, you can find the English meanings of the words below) satı̧ fiyatı: Sale Cost satış hacmi: Sale Value değişken maliyet: Variable Cost sabit maliyet: Fixed Cost kar: Profit 


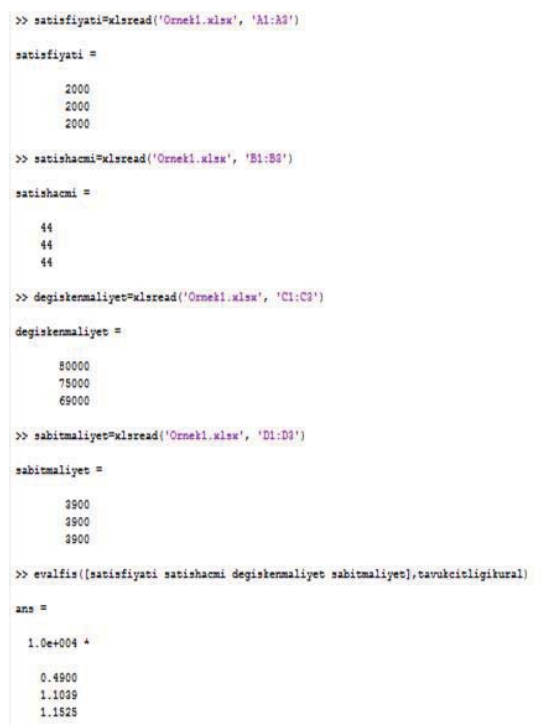

Figure 2: Fuzzy Logic Implementation results

(Increase profits and decrease costs in the target has been identified.)

Variable Cost: $8.000,7.500,6900$

Profit: $(0.4900,1.1039,1.1525) \times 10^{4}$

Definition: To increase profit by reducing the cost required by Target Costing. Fuzzy logic can be provided while reducing the costs have seen profits rise.

(Some words on the figure is written in Turkish, you can find the English meanings of the words below)

satış fiyatı: Sale Cost

satış hacmi: Sale Value

değişken maliyet: Variable Cost

sabit maliyet: Fixed Cost

kar: Profit

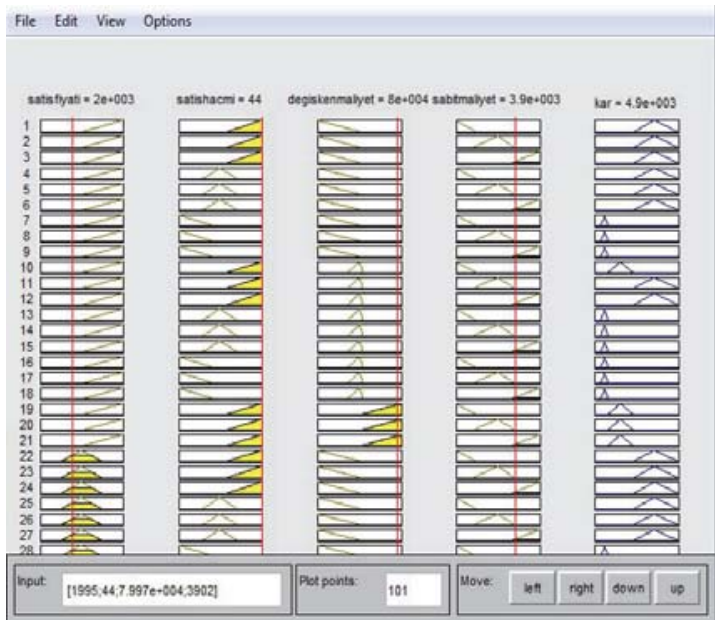

Figure 3: Fuzzy Logic Implementation results. ("Kar" means profit in Turkish) 
(Some words on the figure is written in Turkish, you can find the English meanings of the words below) satı̧ fiyatı: Sale Cost

satış hacmi: Sale Value

değişken maliyet: Variable Cost

sabit maliyet: Fixed Cost

kar: Profit

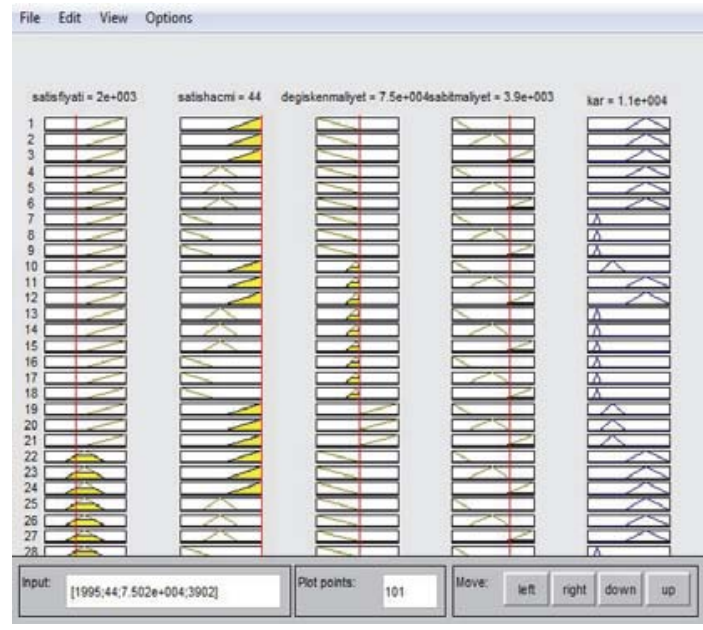

Figure 4: Fuzzy Logic Implementation results.

(Some words on the figure is written in Turkish, you can find the English meanings of the words below) satış fiyatı: Sale Cost

satış hacmi: Sale Value

değişken maliyet: Variable Cost

sabit maliyet: Fixed Cost

kar: Profit

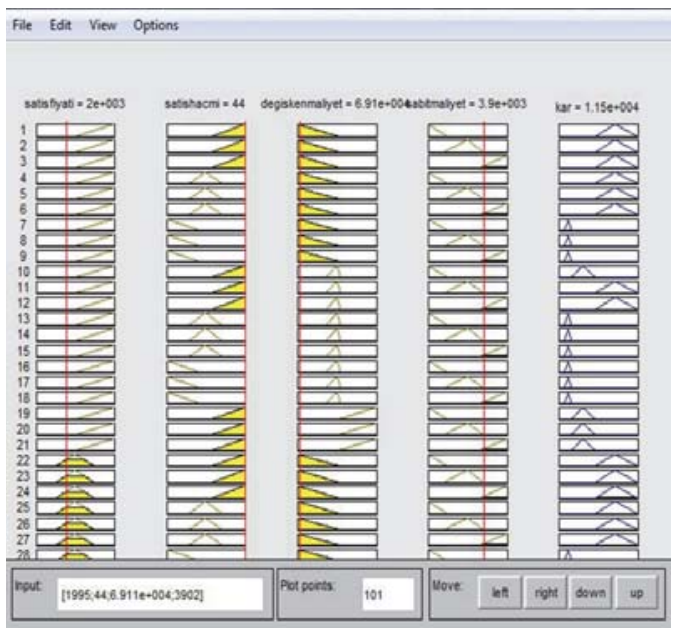

Figure 5: Fuzzy Logic Implementation results. 
(Some words on the figure is written in Turkish, you can find the English meanings of the words below) satı̧ fiyatı: Sale Cost satıs hacmi: Sale Value değişken maliyet: Variable Cost sabit maliyet: Fixed Cost kar: Profit

\section{Results}

It is hereby tried to find what cost has to be in order to reach desired profit rates by considering the product prices and costs during the product design planning process shortly with target costing method. Now the world has become a small global village. Dazzling developments on communication technologies have decreased the duration of answers of What, Where and How much does it Cost? to a just click time. The period of determining rough costs and multiplying the cost 2 or 3 in order to find the right sale cost has ended. Product costs are being known by all shareholders. Manufacturers are not able to determine sale costs as they desired. Buyers press the manufacturer to buy the goods with costs they desired. It is necessary for manufacturers to know the costs and analyse them. It is required to determine the costs during designplan phase and be aware about changes if difference or features are added before the production. Target costing is a method that begins to operate during product design phase and provide connection between profit and cost. It is a method that makes cost management and profit management simultaneously. We tried to find out what the cost has to be in order to reach desired profit with stable sale cost disadvantage in order to reach the targeted profit in specific production volumes. We determined that desired profits can be reached with the change on the costs by performing applications with Fuzzy Logic Theory. As we decreased running cost by costs, we have reached desired profit rates. We have seen that the profit is raised as we decrease the cost. We determined the effects of variations on the profit planning and costing of business with Fuzzy Logic Theory. We have seen that Fuzzy Logic Theory allows easy, practical, prototype target costing applications.

\section{References}

Akgüç, Öztin. (1998), Financial Management, Institute of Accounting, Issue No:65 Institute of Engineering, Education and Research Foundation, No:17, p:393, İstanbul

Alagöz, A and Ceran, Y. (2006), Target Cost Management as a Strategic Cost and Profit Planning Tool, Selçuk University Journal of Social Sciences.

Büyükmirza, Kamil (2006), Cost and Management Account, Gazi Kitabevi, Ankara.

Can, A. Vecdi, (2004), Target Cost, Theory and Application, Sakarya Kitabevi, Sakarya.

Coşkun, A. (2003), Target Cost Management as a Strategic Cost Management Tool, Journal of Academic Researches, Issue:15.

Elmas, Çetin (2003), Fuzzy Auditors (Theory, Application, Neural Fuzzy Auditors), Seçkin Yayıncılık, P:27

Gökçen, Gürbüz, (2003), Cost Targeting as Cost Reduction Approach, Journal of Accounting and Finance, Issue: 20.

Karakaya, Mevlüt. (2004), Cost Accounting, Gazi Kitabevi,Ankara.

Öndaş, Alp.(2003), A Rational Understanding at Cost Management: Cost Targeting, Journal of Financial Solution, Issue: 65.

Şen, Z. (2004), Modelling Principles in Engineering with Fuzzy Logic, Water Foundation Publications, s.9

Yuan, Fong Ching (2007), The Use of a Fuzzy Logic Based System in Cost-Volume-Profit Analysis Under Uncertainty, www.science direct.com 